\title{
Language differences in verbal short-term memory do not exclusively originate in the process of subvocal rehearsal
}

\author{
ANNABEL S. C. THORN and SUSAN E. GATHERCOLE \\ University of Bristol, Bristol, United Kingdom
}

\begin{abstract}
Language differences in verbal short-term memory were investigated in two experiments. In Experiment 1, bilinguals with high competence in English and French and monolingual English adults with extremely limited knowledge of French were assessed on their serial recall of words and nonwords in both languages. In all cases recall accuracy was superior in the language with which individuals were most familiar, a first-language advantage that remained when variation due to differential rates of articulation in the two languages was taken into account. In Experiment 2, bilinguals recalled lists of English and French words with and without concurrent articulatory suppression. First-language superiority persisted under suppression, suggesting that the language differences in recall accuracy were not attributable to slower rates of subvocal rehearsal in the less familiar language. The findings indicate that language-specific differences in verbal short-term memory do not exclusively originate in the subvocal rehearsal process. It is suggested that one source of language-specific variation might relate to the use of long-term knowledge to support short-term memory performance.
\end{abstract}

Cross-linguistic differences in verbal short-term memory capacity are well documented. The majority of research has used digit span as the principal measure of memory performance and has demonstrated significant variation in recall accuracy when digit span is assessed in different languages (Hoosain, 1982, 1984; Naveh-Benjamin \& Ayers, 1986; Stigler, Lee, \& Stevenson, 1986). For example, in a language such as Chinese, digit span can be as high as 9.9 (Hoosain, 1984), whereas in English spans are typically smaller, ranging from 2 to 3 digits for children to 7 digits for adults (Gathercole \& Baddeley, 1993). The principal theoretical explanation for cross-linguistic variation attributes language differences to a well-established short-term memory phenomenon known as the word length effect. Within a language, memory performance is consistently found to be superior for short as compared with long words (Baddeley, Thomson, \& Buchanan, 1975). In the phonological loop component of the working memory model (Baddeley, 1986; Baddeley \& Hitch, 1974), this phenomenon is accounted for in terms of a rehearsal mechanism that serves to refresh decaying representations held in a phonological short-term store. It is proposed that

This research was supported by a University of Bristol postgraduate scholarship awarded to A.S.C.T. The experimental data for 12 of the native French participants in Experiment 1 was collected in Paris, France and was supported by a British Psychological Society postgraduate travel award to A.S.C.T. The cooperation of the British Institute in Paris is gratefully acknowledged. Correspondence should be addressed to A. S. C. Thorn, Department of Experimental Psychology, University of Bristol, 8 Woodland Road, Bristol, BS8 1TN, England (e-mail: annabel.thorn@bristol.ac.uk). word length effects arise because words that take longer to produce are correspondingly rehearsed more slowly, resulting in an increased chance of loss from the phonological store through trace decay (Baddeley, Lewis, \& Vallar, 1984; Baddeley et al., 1975). Cross-linguistic differences in memory capacity are thought to arise in a similar way; languages such as Chinese, in which digit names are short, are thought to permit faster subvocal rehearsal, resulting in better recall performance. Consistent with this proposal, cross-linguistic comparisons of verbal short-term memory capacity typically show a strong inverse relationship between digit span and the spoken duration of digit names in different languages (Hoosain, 1982, 1984; NavehBenjamin \& Ayres, 1986; Stigler et al., 1986).

Language differences in short-term memory performance are not only found cross-linguistically but have also been demonstrated in bilingual individuals (e.g., Chincotta \& Hoosain, 1995; Chincotta \& Underwood, 1996, 1997; Da Costa Pinto, 1991). For example, in a commonly cited set of experiments, Ellis and Hennelly (1980) showed that Welsh-English bilinguals had superior digit span in the language with the shorter digit names (English), despite the fact that these individuals' self-rated proficiency was greater in Welsh than in English. This, and the absence of a language difference under experimental conditions that disrupt subvocal rehearsal, led the authors to claim that bilingual language differences in recall performance, like cross-linguistic differences, can be attributed to subvocal rehearsal rate differences. A number of methodological concerns with the Ellis and Hennelly study have now been identified, however (Chincotta \& Underwood, 1997). Indeed, attempts to replicate their findings have 
produced equivocal results (see, e.g., Brown \& Hulme, 1992; Cheung \& Kemper, 1993; Chincotta \& Hoosain, 1995; Chincotta \& Underwood, 1996, 1997; Da Costa Pinto, 1991), casting doubt on the view that subvocal rehearsal rate differences are solely responsible for language differences in bilingual memory performance.

One interesting feature of the original Ellis and Hennelly (1980) study is that not only were the English digit names shorter than Welsh digit names but, as a consequence of schooling methods, they were also likely to be more familiar to the bilingual participants. One possibility therefore is that the English language advantage in digit span could in part reflect a difference in digit name familiarity. There is growing evidence for the influence of familiarity with a language on verbal short-term memory capacity. One such influence relates to knowledge of words in the mental lexicon. Immediate serial recall is consistently found to be better for words than for nonwords, a lexicality effect that is independent of the articulatory duration of the memory items and that relates to their phonological rather than semantic properties (Hulme, Maughan, \& Brown, 1991; Hulme, Roodenrys, Brown, \& Mercer, 1995; Roodenrys, Hulme, \& Brown, 1993; see also Brown \& Hulme, 1992). The superior recall of words over nonwords has led to the suggestion that immediate memory performance is in some way enhanced by prior phonologically based lexical knowledge; nonwords are unable to benefit from such support because no long-term representation exists for unfamiliar word forms (Hulme et al., 1991). A second type of long-term knowledge support relates to knowledge concerning the phonotactic properties of a language; for unfamiliar words (or nonwords whose phonological structure conforms to the phonotactics of the language), those items that contain high-probability phoneme combinations are better recalled than those containing low-probability phoneme combinations (Gathercole, Frankish, Pickering, \& Peaker, 1999; see also Gathercole, 1995; Gathercole, Willis, Emslie, \& Baddeley, 1991; Grant et al., 1997; van Bon \& van der Pij1, 1997).

The use of long-term lexical and phonotactic knowledge to enhance immediate memory capacity provides a plausible source of language-specific differences in recall performance. According to this account, when individuals have differing levels of familiarity with two languages, language-specific differences in recall accuracy will arise from the differential availability of long-term knowledge about the structure of each language with which to support immediate memory functioning. Previous studies of bilingual language differences in recall accuracy are likely to have provided the most conservative estimate of such an influence since the majority used digit span to measure immediate memory capacity; digits are learned relatively early during language acquisition and are therefore most likely to benefit from long-term knowledge support in recall. In contrast, recent examinations of recall accuracy for nondigit words in bilingual children suggest that language differences in memory per- formance may well arise as a consequence of differences in the availability of long-term knowledge support in each language (Chincotta \& Underwood, 1998; Thorn \& Gathercole, 1999).

The two experiments reported in this article were designed to examine whether language differences in memory capacity in adult bilinguals are solely due to subvocal rehearsal rate differences or might also reflect nonarticulatory factors such as long-term knowledge contributions. This possibility was examined in two ways. In Experiment 1 , monolinguals' and bilinguals' recall accuracy was assessed for nondigit words and also for unfamiliar nonwords in English and in French; differences in articulation rates were statistically controlled. In Experiment 2, bilinguals' recall performance in both their languages was assessed under experimental conditions that disrupted subvocal rehearsal. If, as proposed, language-specific variation in memory performance does not exclusively originate in the process of subvocal rehearsal, then firstlanguage superiority should be observed in the immediate memory performance of these individuals even when differences in rate of articulation are controlled for or subvocal rehearsal is disrupted. Furthermore, if differences in long-term knowledge of a language are important, the greatest language difference in recall accuracy should be observed for the monolingual adults, for whom the difference in language familiarity is greatest.

\section{EXPERIMENT 1}

\section{Method}

Participants. A total of 32 adult proficient second-language speakers took part in this experiment. For the purposes of this article, this group will be termed the "bilinguals." Sixteen members of the group were native English speakers (11 female and 5 male), and the remaining 16 members were native French speakers (all female). This bilingual group composition was employed in order to identify language familiarity differences in memory capacity that are independent of differences related to the particular languages spoken by the bilinguals. The mean age of this group was 42 years 7 months $(S D=13$ years 9 months, range $=23$ years 0 months to 73 years 0 months), and the mean age at which second-language acquisition began was 13 years 5 months $(S D=6$ years 10 months, range $=6$ years 0 months to 42 years 0 months).

The second group consisted of 16 English adults (11 female and 5 male) with very limited knowledge of French. For the purposes of this article, this group will be referred to as the "monolingual" group, although it is acknowledged that members of the group had some basic knowledge of French. The monolingual participants were of a comparable age to the bilinguals, with a mean age of 42 years 1 month $(S D=17$ years 0 months, range $=20$ years 0 months to 71 years 0 months).

Each participant completed the senior form of the Mill Hill Vocabulary Scale (Raven, Raven, \& Court, 1988), which was translated into French by a native French speaker to provide an equivalent measure of French vocabulary knowledge. The English test responses were scored by a native English speaker, and responses to the French version of the test were scored by a native French speaker.

Table 1 shows the mean raw vocabulary scores (maximum score $=$ 88 ) obtained by the bilingual and monolingual groups on the vocabulary measure in each language. The bilingual participants showed superior vocabulary knowledge in their first relative to their second 
Table 1

Mean Scores on the Vocabulary, Recall, and Articulation Rate Measures as a Function of Language Group in Experiment 1

\begin{tabular}{|c|c|c|c|c|c|c|c|c|}
\hline \multirow[b]{4}{*}{ Measure } & \multicolumn{8}{|c|}{ Language Group } \\
\hline & \multicolumn{4}{|c|}{ Bilingual } & \multicolumn{4}{|c|}{ Monolingual } \\
\hline & \multicolumn{2}{|c|}{ First Language } & \multicolumn{2}{|c|}{ Second Language } & \multicolumn{2}{|c|}{$\begin{array}{l}\text { First Language } \\
\text { (Native) }\end{array}$} & \multicolumn{2}{|c|}{$\begin{array}{l}\text { Second Language } \\
\text { (Foreign) }\end{array}$} \\
\hline & $M$ & $S D$ & $M$ & $S D$ & $M$ & $S D$ & $M$ & $S D$ \\
\hline Vocabulary & 75.47 & 8.05 & 58.34 & 10.21 & 66.75 & 6.92 & - & - \\
\hline \multicolumn{9}{|l|}{ Recall } \\
\hline Words & 9.58 & 1.70 & 7.45 & 1.52 & 8.52 & 1.70 & 3.71 & 1.94 \\
\hline Nonwords & 4.96 & 1.36 & 3.72 & 1.18 & 3.90 & 1.55 & 1.71 & 1.15 \\
\hline \multicolumn{9}{|c|}{ Articulation rate } \\
\hline Words & 1.92 & 0.32 & 1.56 & 0.26 & 1.88 & 0.29 & 1.48 & 0.24 \\
\hline Nonwords & 1.65 & 0.30 & 1.41 & 0.21 & 1.68 & 0.29 & 1.25 & 0.22 \\
\hline
\end{tabular}

Note-The French vocabulary task was not completed by participants in the monolingual group.

Articulation rates are given in items/second.

language. A one-way analysis of variance (ANOVA) applied to the raw vocabulary scores indicated signif icantly better first-language vocabulary knowledge $[F(1,31)=80.46, p<.001]$. Corresponding percentile grades, based on the original English version of the task (Raven, Court, \& Raven, 1994), indicated that the bilinguals had above-average knowledge of first-language vocabulary and average knowledge of second-language vocabulary. The monolingual group showed a slightly lower level of knowledge of their native language vocabulary than the bilingual group. A one-way ANOVA applied to the percentile grades indicated that the difference between the monolinguals' and bilinguals' knowledge of their native language vocabulary was significant $[F(1,47)=10.34, p<.01]$. The monolingual group did not complete the French version of the vocabulary test.

Design and Materials. Recall accuracy was assessed in both English and in French for words and nonwords of two, three, and four syllables in length. In each condition stimuli were taken from eight-item closed sets. ${ }^{1}$ The words in each set were matched for conceptual category and word frequency. Frequency measures for the English words were obtained from the CELEX psycholinguistic database (Baayen, Piepenbrock, \& van Rijn, 1993); French word frequency measures were based on their English translation equivalent. The words were selected on the basis of their likely familiarity to the bilingual participants, with the restriction that the French words should be unfamiliar to the monolingual English participants. To confirm familiarity with the word stimuli, the bilingual participants were asked to identify, from a list presented before testing commenced, which if any of the 24 words they had not come across in their second language. The mean number of second-language words that were unfamiliar to the bilingual participants was 2.8 $(S D=2.6$, range $=0-8)$. The mean number of French words that were unfamiliar to the monolingual participants was $19.6(S D=$ 1.5 , range $=18-23$ ). The English nonwords were taken from the Children's Test of Nonword Repetition (Gathercole \& Baddeley, 1996; Gathercole, Willis, Baddeley, \& Emslie, 1994), and these were matched as closely as possible for wordlikeness values with French nonwords selected from a French nonword corpus (Thorn \& Gathercole, 1999).

The tests were administered in two blocks; Block A consisted of the English version of each measure, and the French versions of the tests were presented in Block B. The order of presentation of the two testing blocks was counterbalanced within groups. In each testing block the word recall task was administered first, followed by the nonword recall task. Within each category (English and French words and nonwords), the order of presentation of the three stimulus lengths was randomized. Sequence lists were constructed by sampling randomly and without replacement from each stimulus set. Recordings of the spoken form of each stimulus item were taken from native speakers of the two languages and audiocassette recordings of the sequence lists were subsequently produced by sampling the single instance of each stimulus as required.

Procedure. The two testing blocks were administered at least $24 \mathrm{~h}$ apart. Each test session was conducted in English.

For the immediate recall task, items were presented auditorily at a rate of one item per $1.75 \mathrm{sec}$. There were three lists at each list length, and lists increased in length by one item at each increment. In each case, testing commenced at a sequence length of two items and ceased when the participant failed to recall correctly two of the three lists at a particular list length. A spoken output procedure was used, and recall score was calculated as the number of lists recalled correctly up to span (where span was the list length immediately preceding the length at which participants failed to recall two out of the three lists).

For the articulation rate measure, participants were required to repeat pairs of items in each stimuli set 10 times as quickly and accurately as possible. Responses were recorded on an audiocassette and were subsequently examined using sound editing software. Rates of articulation were calculated by averaging the time taken to repeat 10 pairs and converting this to give a mean articulation rate in terms of items per second.

\section{Results and Discussion}

Performance of the bilingual and monolingual groups on the word and nonword recall and articulation rate measures, collapsed across syllable length, ${ }^{2}$ is summarized in Table 1 . Note that for the bilingual group the data presented in this table and in subsequent analyses are reported according to whether the language was the participants' first (native) or second language. Thus "first-language" scores are based on performance on the English versions of each measure for the native English bilinguals and on the French test scores for the native French bilinguals.

Consider first the recall performance of the two groups. Both the bilingual and the monolingual groups showed superior recall accuracy for both words and nonwords in their first language. The monolingual participants showed a much larger difference in their recall of words and in their recall of nonwords in the two languages, reflecting 
the greater difference in their familiarity with the two languages.

An ANOVA was conducted on the recall scores as a function of language (first or second), lexicality (word or nonword), and language group (bilingual or monolingual). This analysis established a significant main effect of language $[F(1,46)=233.30, p<.001]$, arising from greater recall accuracy in the first than the second language. A significant effect of lexicality was also established $[F(1,46)=477.83, p<.001]$, reflecting superior recall of words than nonwords. The group term was also significant $[F(1,46)=28.53, p<.001]$, reflecting greater recall accuracy for the bilingual than for the monolingual participants. The analysis further established a significant interaction between group and language $[F(1,46)=$ $28.48, p<.001]$. Exploration of this term using simple main effects analysis indicated a significant effect of language for both the bilingual group $[F(1,31)=59.77, p<$ $.001]$ and the monolingual group $[F(1,15)=315.00, p<$ $.001]$, while the group effect was significant for both the first $[F(1,46)=6.23, p<.05]$ and second $[F(1,46)=$ $55.75, p<.001]$ languages. Examination of the means suggests that the interaction reflects a larger language effect for the monolingual group than for the bilingual group. The interactions between language and lexicality and between group and lexicality were both significant $[F(1,46)=41.14, p<.001$, and $F(1,46)=6.37, p<.05$, respectively], as was the three-way interaction between language, lexicality, and group $[F(1,46)=9.92, p<.01]$. Simple main effects indicated a significant language effect for words and nonwords for both the bilingual group $[F(1,31)=50.28, p<.001$, and $F(1,31)=26.26, p<$ .001 , respectively $]$ and the monolingual group $[F(1,15)=$ $206.77, p<.001$ and $F(1,15)=26.26, p<.001$, respectively]. One possibility is that the language effect for words for the bilingual group reflects a type of lexicality effect, obtained because a minority of the second-language words were not familiar to some of the bilingual participants. By this account, a smaller lexicality effect should be observed in the second language than in the first language for the bilingual group, reflecting the fact that in the second language some of the words were in effect nonwords to the participants. Simple main effects analysis indicated a significant lexicality effect for the bilingual group for both the first and second languages $[F(1,31)=292.23$, $p<.001$, and $F(1,31)=214.48, p<.001$, respectively]. The strength of association between lexicality and recall performance in each language was estimated by calculating partial $\eta^{2}$, a measure of the proportion of variance in recall performance that is associated with lexicality. For the first language, partial $\eta^{2}$ was .90; for the second language, partial $\eta^{2}$ was .87 , indicating a comparable impact of lexicality on recall performance in the first and second languages.

The pattern of recall accuracy shown by the two language groups therefore indicated superior recall accuracy of both familiar words and unfamiliar nonwords in the first than in the second language for both the monolingual group and the bilingual group. In the present ex- periment, variation in the articulatory duration of the stimuli per se is unlikely to be responsible for the observed first-language superiority in recall accuracy for the bilingual group, since for half of the group the first-language stimuli were the English memory items, whereas for the remaining members of the group the first-language stimuli were the French memory items. However, there is some evidence that rate of articulation itself is influenced by language familiarity (Chincotta \& Hoosain, 1995; Chincotta \& Underwood, 1996), and so it remains plausible that the first-language superiority in immediate recall found here may be attributable to this alternative source of differential rates of articulation for stimuli in the two languages.

Table 1 shows the mean rates of articulation (items per second), collapsed across syllable length, obtained for the bilingual and monolingual language groups as a function of stimulus type. Both the bilingual group and the monolingual English participants were faster at articulating both words and nonwords in their more familiar language. The correlation between articulation rate and recall score across the data set was $r(576)=.60, p<.001$, indicating a significant relationship between rate of articulation and memory performance.

One method of assessing the effect of articulation rate on recall accuracy is to examine memory performance with an analysis of covariance (ANCOVA) in which articulation rate is entered as a covariate. Such an analysis permits evaluation of language differences in recall accuracy while adjusting for the effects of speech rate on memory performance. The memory recall scores obtained for the bilingual and monolingual groups were therefore subjected to a three-way ANCOVA, conducted as a function of language (first or second), lexicality (word or nonword), and group (bilingual or monolingual), in which the articulation rate measures, collapsed over syllable length, were entered as a varying covariate. In this analysis the main effect of language remained significant $[F(1,45)=$ $35.96, p<.001]$, indicating that the memory advantage in the first language was not attributable to differential rates of articulation for stimuli in the two languages. The lexicality term also remained significant $[F(1,45)=$ $66.85, p<.001$ ], replicating previous findings (Hulme et al., 1995) that the superiority of memory performance for words over nonwords is not simply due to faster rates of articulation for words than for nonwords. The group effect also remained significant $[F(1,45)=27.09, p<$ $.001]$, as did the interaction between group and language $[F(1,45)=22.66, p<.001]$. This term was explored with a simple main effects analysis, which indicated a significant language effect for both the bilingual group $[F(1,30)=$ $9.97, p<.01]$ and the monolingual group $[F(1,14)=$ $28.46, p<.001]$, and a significant group effect for both the first $[F(1,45)=6.13, p<.05]$ and second $[F(1,45)=$ $51.44, p<.001]$ languages. The language $\times$ lexicality and the group $\times$ lexicality interactions also remained significant in this analysis $[F(1,45)=37.43, p<.001$, and $F(1,45)=6.38, p<.05$, respectively], as did the threeway interaction $[F(1,45)=9.49, p<.01]$. Exploration of 
this term using simple main effects analysis indicated a significant language effect for nonwords for the bilingual group $[F(1,30)=13.59, p<.01]$ and for words for the monolingual group $[F(1,14)=36.63, p<.001]$. However, the language effect for words for the bilingual group and for nonwords for the monolingual group was nonsignificant $[F(1,30)=2.33, p>.05$, and $F(1,14)=3.89$, $p>.05$, respectively].

The ANCOVA applied to the recall data for the two language groups therefore established equivocal results with respect to the influence of articulation rate on recall accuracy. For the monolingual group, it seems likely that the magnitude of the language effect for nonwords might have been diminished by levels of recall accuracy that were approaching floor performance. However, for the bilingual group the ANCOVA suggests that the first-language advantage in word recall might be attributable to differences in rates of articulation in the two languages. An alternative technique for examining variation in memory performance that is independent of differential rates of articulation for memory items is to compare performance for stimuli of matched articulatory duration. Memory performance for the bilingual group was therefore compared for selected words in the first and second languages, matching for articulation rates in the two languages. Recall scores for three-syllable words in the first language (mean recall score $=10.00, S D=2.23$; mean articulation rate $=1.83 \mathrm{items} / \mathrm{sec})$ were compared with those of twosyllable words in the second language (mean recall score $=$ $8.38, S D=1.83$; mean articulation rate $=1.95$ items/ $\mathrm{sec}$ ), giving a slight articulation rate advantage to the second language. A paired samples $t$ test established a significant difference in memory performance reflecting superior recall in the first relative to the second language $[t(31)=4.21, p<.001]$, indicating that even though items were matched for articulatory duration, memory performance was still better in the first than in the second language.

In Experiment 2, the influence of rate of articulation on bilinguals' word recall was examined by considering memory performance under experimental conditions designed to disrupt subvocal rehearsal, the process that, according to the working memory model, underlies the relationship between articulation rate and recall accuracy (Baddeley et al., 1984; Baddeley et al., 1975). If differences in rate of subvocal rehearsal are not responsible for first-language superiority in memory performance, then superior recall in the first language should persist when rehearsal is disrupted in this way.

\section{EXPERIMENT 2}

\section{Method}

Participants. Twelve native French adults, 11 female and 1 male, took part in this experiment. The mean age of this group was 27 years 3 months $(S D=7$ years and 9 months, range $=20$ years 6 months to 46 years 0 months), and the mean age at which they had begun learning English was 11 years 0 months $(S D=3$ years and 7 months, range $=2$ years 0 months to 17 years 0 months).
Table 2

Mean Scores on the Vocabulary and Recall Measures as a Function of Language in Experiment 2

\begin{tabular}{lrrrrr}
\hline & \multicolumn{4}{c}{ Language } \\
\cline { 2 - 3 } \multicolumn{1}{c}{ Measure } & \multicolumn{3}{c}{ First Language } & & \multicolumn{2}{c}{ Second Language } \\
\cline { 2 - 3 } \cline { 5 - 6 } & $M$ & $S D$ & & $M$ & $S D$ \\
\hline Vocabulary & 78.83 & 4.51 & 60.08 & 6.87 \\
List recall & & & & \\
$\quad$ Without suppression & 11.83 & 2.48 & & 10.33 & 2.90 \\
$\quad$ With suppression & 9.58 & 2.50 & & 7.33 & 1.44 \\
\hline
\end{tabular}

Vocabulary knowledge was assessed using the senior form of the Mill Hill Vocabulary Scale (Raven et al., 1988) in French and in English (see Experiment 1). Table 2 shows the mean scores obtained on this measure in each language. The bilinguals scored higher on the French vocabulary measure than on the English version of the task. The corresponding percentile grades (Raven et al., 1994) indicated that knowledge of first-language vocabulary was above average, and knowledge of second-language vocabulary was average. A one-way ANOVA applied to the raw scores as a function of language (first or second) established that the difference in vocabulary knowledge in the two languages was significant $[F(1,11)=$ $106.87, p<.001]$.

Design and Materials. Immediate recall accuracy was assessed for words in French and in English with and without concurrent articulatory suppression. The order of administration of the control and suppression conditions was counterbalanced, and within each condition the order of presentation of the English and French versions of the task was counterbalanced. The stimuli were taken from the word recall task used in Experiment 1, and their selection was based on the articulation rate data for the native French speakers in that experiment: The French stimuli were the three-syllable words from Experiment 1 (mean articulation rate $=1.77$ words $/ \mathrm{sec}$ ) while the English stimuli were the two-syllable words from Experiment 1 (mean articulation rate $=1.92$ words/sec), giving an articulatory duration advantage to stimuli in the second language (the English words). All participants confirmed that they were familiar with the English words before testing commenced. Recall lists were constructed by sampling randomly and without replacement from the two word sets. In each case two sets of lists were constructed, the use of which was counterbalanced between the with and without articulatory suppression conditions. Audio cassette recordings of the lists were produced following the procedure described in Experiment 1.

Procedure. Each participant was tested individually in one testing session. In each condition the participant was required to recall a sequence of words immediately after presentation. Words were presented auditorily at a rate of 1 item per $1.75 \mathrm{sec}$. Testing commenced with three-item lists and participants received four lists at each of four list lengths (three, four, five, and six items). In the suppression condition, participants repeated the numbers "one, two, three" in the task language during both presentation and recall (Baddeley et al., 1984), while in the control condition they completed the recall task in silence. As a consequence of the requirement to maintain articulatory suppression during output of the memory list, participants provided a written record of their response (cf. Experiment 1 , in which recall was spoken). To control for differential output demands (Baddeley et al., 1984), participants were required to give only the first syllable of each word. Recall score was recorded as the number of lists recalled correctly (maximum $=16$ ). Four practice lists were given at the beginning of the session.

\section{Results and Discussion}

Descriptive statistics are provided in Table 2. Note that to maintain consistency across experiments, in this table and in the analyses reported in this section, scores 
on the French and English measures are reported as firstand second-language scores, respectively.

A highly consistent pattern of performance was found on the word recall task in the two experimental conditions, with higher recall scores being obtained in the first than second language in both the with and without articulatory suppression conditions. A two-way ANOVA, conducted as a function of language (first or second) and suppression condition (with or without articulatory suppression) established a significant main effect of language $[F(1,11)=$ $20.57, p<.01]$, reflecting superior recall of words in the first than in the second language. The suppression condition term was also significant $[F(1,11)=25.22, p<$ $.001]$, arising from the deleterious effect of concurrent articulatory suppression on memory performance. Importantly, the interaction between language and suppression condition was nonsignificant $[F(1,11)=0.71, p>$ $.05]$, indicating that the first-language advantage when recall accuracy was assessed without articulatory suppression was not significantly diminished when recall accuracy was assessed under concurrent articulatory suppression. The persistence of first-language superiority in recall accuracy when subvocal rehearsal was disrupted by concurrent irrelevant articulation provides strong evidence that the language effect does not exclusively arise in the subvocal rehearsal process.

\section{GENERAL DISCUSSION}

The two experiments presented in this article investigated the hypothesis that language differences in bilingual short-term memory arise exclusively in the process of subvocal rehearsal. In both cases, no support for this hypothesis was found. In Experiment 1, bilinguals showed superior recall of both familiar words and phonotactically legal nonwords in their most familiar language, a first-language advantage that persisted when differences in rates of articulation in the two languages were controlled. Interestingly, the magnitude of the language difference in recall performance shown by the monolingual participants in this experiment was greater than that of the bilinguals, indicating that recall accuracy in each language was closely associated with degree of language familiarity. Further evidence that subvocal rehearsal rate differences are not exclusively responsible for first-language memory superiority was provided in Experiment 2, in which bilinguals showed better recall of first- than secondlanguage words, even when subvocal rehearsal was disrupted by concurrent irrelevant articulation.

So why does first-language superiority persist when subvocal rehearsal rate differences are accounted for? One possibility, considered earlier, is that language differences in recall reflect the use of long-term knowledge to support recall performance. Within a particular language it is consistently found that familiar words are recalled better than are unfamiliar nonwords (Hulme et al., 1991) and that highly wordlike nonwords are more accurately recalled than non-wordlike nonwords (Gather- cole, 1995; Gathercole et al., 1999; Gathercole et al., 1991; Grant et al., 1997; van Bon \& van der Pijl, 1997). It has been suggested that these phenomena arise from the use of long-term representations of phonological information, both of the phonological structure of specific lexical items and of the phonotactic properties of a language (Gathercole et al., 1999), to support the recall of degraded memory traces held in the phonologicalstore. One suggestion is that long-term knowledge is used to "fill in" partially degraded representations during retrieval from the phonological store in a process termed "redintegration" (Brown \& Hulme, 1995, 1996; Hulme et al., 1997; see also Schweickert, 1993). Another suggestion is that support from long-term phonological knowledge occurs "on-line" with familiar sound patterns being more readily represented in the phonological store than less familiar sound patterns (Gathercole \& Martin, 1996; see also Gupta \& MacWhinney, 1997; Martin \& Saffran, 1992). The extent to which a single mechanism is responsible for all long-term knowledge effects is not yet clear. Indeed, it is entirely plausible that both redintegrative and "on-line" mechanisms operate during short-term recall, but mediate the use of dissociable levels of longterm knowledge.

Both redintegrative and on-line accounts can accommodate language familiarity differences in short-term recall. By a redintegrative account, language differences arise as a consequence of differences in the availability of lexical and phonological long-term knowledge with which to reconstruct decayed representations in familiar and less familiar languages. According to this analysis, monolingual individuals will not benefit from redintegration in the recall of foreign language stimuli as a consequence of the absence of long-term knowledge about the language with which to reconstruct degraded traces. In this situation, recall will be based only on the contents of the phonological store. In contrast, when an individual knows two languages equally well, the possibility for reconstruction will be equivalent in each language, resulting in comparable recall support. Consistent with this suggestion, "native bilinguals" (individuals who have acquired two languages from birth and as a consequence have equivalent knowledge of both languages) show comparable recall accuracy in their two languages (Thorn \& Gathercole, 1999). Importantly, by a redintegrative account, when a bilingual has asymmetric knowledge of two languages, the knowledge differential means more support is available for reconstruction of degraded traces in the first than second language, resulting in a first-language memory advantage.

By contrast, in an on-line account, long-term knowledge is proposed to support memory performance by selectively increasing the levels of activation of information in the short-term store (Gathercole, 1997; Gathercole \& Martin, 1996; Gupta \& MacWhinney, 1997; Martin \& Saffran, 1992; McClelland \& Elman, 1986). In this type of account, the contents of the phonological store can be conceived of as patterns of activation across a network of 
phonological units, in which long-term knowledge determines the strength of connections between units. By this analysis, language differences in memory performance arise as a consequence of differences in the extent to which connections within the network reflect the lexical and phonological structure of the test language. When two languages are acquired in parallel and are equally well known, the network should embody the phonological structure of both languages so that verbal information in either language is equally well represented. When one language is more familiar than another, however, connections in the network will predominantly reflect the phonological structure of the more familiar language, with the result that novel phonological information will achieve higher activation levels if it conforms to the structure of the first rather than the second language.

The data obtained in Experiments 1 and 2 did not provide the opportunity to distinguish between an account of language familiarity effects in terms of redintegrative or more on-line long-term knowledge support. What the present data do clearly demonstrate is that, contrary to previous suggestions (e.g., Ellis \& Hennelly, 1980), language differences in bilingual short-term memory performance are not mediated exclusively by subvocal rehearsal rate differences. A key issue for future research is to identify what additional mechanisms underlie firstlanguage superiority in verbal short-term memory. We suggest that one possibility is that language-specific variation in bilingual recall accuracy is also determined by the availability of suitable language-dependent long-term knowledge with which to support recall performance.

\section{REFERENCES}

Batyen, R. H., Piepenbrock, R., \& Rijn, H. (1993). The CELEX lexical database [CD-ROM]. Philadelphia: University of Pennsylvania, Linguistic Data Consortium.

BADDELEy, A. D. (1986). Working memory. Oxford: Oxford University Press.

Baddeley, A. D., \& Hitch, G. (1974). Working memory. In G. H. Bower (Ed.), The psychology of learning and motivation (Vol. 8, pp. 47-90). New York: Academic Press.

Baddeley, A. D., Lewis, V. J., \& Vallar, G. (1984). Exploring the articulatory loop. Quarterly Journal of Experimental Psychology, 36A, 233-252.

Baddeley, A. D., Thomson, N., \& Buchanan, M. (1975). Word length and the structure of short-term memory. Journal of Verbal Learning \& Verbal Behaviour, 14, 575-589.

Brown, G. D. A., \& Hulme, C. (1992). Cognitive psychology and second language processing: The role of short-term memory. In R. J. Harris (Ed.), Cognitive processing in bilinguals (pp. 105-121). Amsterdam: Elsevier.

Brown, G. D. A., \& Hulme, C. (1995). Modelling item length effects in memory span: No rehearsal needed? Journal of Memory \& Language, 34, 594-621.

Brown, G. D. A., \& Hulme, C. (1996). Nonword repetition, STM, and word age-of-acquisition: A computational model. In S. E. Gathercole (Ed.), Models of short-term memory (pp. 129-148). Hove, U.K.: Psychology Press.

Cheung, H., \& Kemper, S. (1993). Recall and articulation of English and Chinese words by Chinese-English bilinguals. Memory \& Cognition, 21, 666-670.

Chincotta, D., \& Hoosain, R. (1995). Reading rate, articulatory sup- pression and bilingual digit span. European Journal of Cognitive Psychology, 7, 201-211.

Chincotta, D., \& Underwood, G. (1996). Mother tongue, language of schooling and bilingual digit span. British Journal of Psychology, 87, 193-208.

Chincotta, D., \& Underwood, G. (1997). Bilingual memory span advantage for Arabic numerals over digit words. British Journal of Psychology, 88, 295-310.

Chincotta, D. \& Underwood, G. (1998). Non-temporal determinants of bilingual memory capacity: The role of long-term representations and fluency. Bilingualism: Language \& Cognition, 1, 117-130.

Da Costa Pinto, A. (1991). Reading rates and digit span in bilinguals: The superiority of mother tongue. International Journal of Psychology, 26, 471-483.

Ellis, N. C., \& Hennelly, R. A. (1980). A bilingual word-length effect: Implications for intelligence testing and the relative ease of mental calculation in Welsh and English. British Journal of Psychology, 71, 43-52.

Gathercole, S. E. (1995). Is nonword repetition a test of phonological memory or long-term knowledge? It all depends on the nonwords. Memory \& Cognition, 23, 83-94.

Gathercole, S. E. (1997). Models of verbal short-term memory. In M. A. Conway (Ed.), Cognitive models of memory (pp. 13-45). Hove, U.K.: Psychology Press.

Gathercole, S. E., \& Baddeley, A. D. (1993). Working memory and language. Hillsdale, NJ: Erlbaum.

Gathercole, S. E., \& BadDEley, A. D. (1996). The children's test of nonword repetition. London: Psychological Corp.

Gathercole, S. E., Frankish, C. R., Pickering, S. J., \& Peaker, S. (1999). Phonotactic influences on short-term memory. Journal of Experimental Psychology: Learning, Memory, \& Cognition, 25, 84-95.

Gathercole, S. E., \& Martin, A. J. (1996). Interactive processes in phonological memory. In S. E. Gathercole (Ed.), Models of short-term memory (pp. 73-100). Hove, U.K.: Erlbaum.

Gathercole, S. E., Willis, C. S., Baddeley, A. D., \& Emslie, H. (1994). The Children's Test of Nonword Repetition: A test of phonological working memory. Memory, 2, 103-127.

Gathercole, S. E., Willis, C. S., Emslie, H., \& Baddeley, A. D. (1991). The influence of syllables and wordlikeness on children's repetition of nonwords. Applied Psycholinguistics, 12, 349-367.

Grant, J., Karmiloff-Smith, A., Gathercole, S. E., Paterson, S., Howlin, P., Davies, M., \& Udwin, O. (1997). Phonological shortterm memory and its relationship to language in Williams Syndrome. Cognitive Neuropsychiatry, 2, 81-99.

Gupta, P., \& MacWhinney, B. (1997). Vocabulary acquisition and verbal short-term memory: Computational and neural bases. Brain \& Language, 59, 267-333.

Hoosain, R. (1982). Correlation between pronunciation speed and digit span size. Perceptual \& Motor Skills, 55, 1128.

Hoosain, R. (1984). Experiments on digit spans in the Chinese and English languages. In H. S. R. Kao \& R. Hoosain (Eds.), Psychological studies of the Chinese language (pp. 23-28). Hong Kong: Chinese Language Society of Hong Kong.

Hulme, C., Maughan, S., \& Brown, G. D. A. (1991). Memory for familiar and unfamiliar words: Evidence for a long-term memory contribution to short-term memory span. Journal of Memory \& Language, 30, 685-601.

Hulme, C., Roodenrys, S., Brown, G., \& Mercer, R. (1995). The role of long-term memory mechanisms in memory span. British Journal of Psychology, 86, 527-536.

Hulme, C., Roodenrys, S., Schweickert, R., Brown, G. D. A., MarTin, S., \& StUART, G. (1997). Word-frequency effects on short-term memory tasks: Evidence for a redintegration process in immediate serial recall. Journal of Experimental Psychology: Learning, Memory, \& Cognition, 23, 1217-1232.

Martin, N., \& Saffran, E. M. (1992). A computational account of deep dysphasia: Evidence from a single case study. Brain \& Language, 43, 240-274.

McClelland, J. L., \& Elman, J. L. (1986). The TRACE model of speech perception. Cognitive Psychology, 18, 1-86. 
Naveh-Benjamin, M., \& Ayres, T. J. (1986). Digit span, reading rate, and linguistic relativity. Quarterly Journal of Experimental Psychology, 38A, 739-751.

Raven, J. C., Court, J. H., \& Raven, J. (1994). Manual for Raven's Progressive Matrices and Vocabulary Scales: Section 5A-Mill Hill Vocabulary Scale. Oxford: Oxford Psychologists Press.

Raven, J. C., Raven, J., \& Court, J. H. (1988). The Mill Hill vocabulary scale (revised). Oxford: Oxford Psychologists Press.

Roodenrys, S., Hulme, C., \& Brown, G. (1993). The development of short-term memory span: Separable effects of speech rate and longterm memory. Journal of Experimental Child Psychology, 56, 431-442.

SCHWEICKERT, R. (1993). A multinomial processing tree model for degradation and redintegration in immediate recall. Memory \& Cognition, 21, 168-175.

Stigler, J. W., Lee, S., \& Stevenson, H. W. (1986). Digit memory in Chinese and English: Evidence for a temporally limited store. Cognition, 23, 1-20.
Thorn, A. S. C., \& Gathercole, S. E. (1999). Language-specific knowledge and short-term memory in bilingual and non-bilingual children. Quarterly Journal of Experimental Psychology, 52A, 303-324. van Bon, W. H. J., \& VAN DER PIJL, J. M. L. (1997). Effects of word length and wordlikeness on pseudoword repetition by poor and normal readers. Applied Psycholinguistics, 18, 101-114.

\section{NOTES}

1. The word and nonword stimuli used in these experiments are available from the authors on request.

2. Preliminary analysis indicated that the syllable length term did not qualify any of the effects reported here. To facilitate interpretation, recall scores were therefore collapsed across syllable length.

(Manuscript received August 24, 1999; revision accepted for publication July 27, 2000.) 